UNIVERSUM $\bullet$ Vol. $30 \bullet$ No $2 \cdot 2015 \bullet$ Universidad de Talca

Los restos del buen gobierno o los retos de una ciudadanía para gobernar en Colombia: Un análisis desde el poder político
Leonardo Sabogal
Pp. 237 a 250

\title{
LOS RESTOS DEL BUEN GOBIERNO O LOS RETOS DE UNA CIUDADANÍA PARA GOBERNAR EN COLOMBIA: UN ANÁLISIS DESDE EL PODER POLÍTICO
}

\author{
The ruins of good governance or challenges of citizenship to rule in Colombia: An \\ analysis from the political power \\ Leonardo Sabogal *
}

\section{RESUMEN}

Este trabajo hace parte de los avances de investigación dentro del proyecto sobre la estructura del poder público en Colombia. Contiene un desarrollo relacionado con el análisis al ejercicio de gobierno, a partir del sentido del poder político expuesto en el marco teórico de la política de la liberación y tiene como finalidad, la generación de una propuesta de gobierno ciudadano más justo y democrático (poder político real) como alternativa al modelo de gobierno tradicional y dominante.

Palabras clave: Poder político, gobierno, ciudadanía, principios, democracia.

\begin{abstract}
This work is part of research progress within the project on the structure of public power in Colombia. Contains a related development analysis exercise of government, from the sense of political power discussed in the theoretical framework of liberation politics

\footnotetext{
* Docente e investigador de los programas de Derecho y de Gobierno y Relaciones Internacionales de la Universidad de San Buenaventura Cali. Cali, Colombia. Correo electrónico: 1sabogal2@ usbcali.edo.co
}

Artículo recibido el 25 de enero de 2014. Aceptado el 17 de octubre de 2014. 
and aims, generating a government proposal more just and democratic citizenship (real political power) as an alternative to traditional governance model and dominant.

Keywords: Political power, government, citizenship, principles, democracy.

\section{INTRODUCCIÓN}

Uno de los problemas socio-jurídicos más recurrentes en el ámbito académico en los últimos años, tiene que ver precisamente con el buen gobierno y la democracia. Una relación estrechamente vinculada a la estructura del poder público, a la armonización estatal y por supuesto, al campo político. Tal vez, no exista un solo ciudadano que haya dejado de pronunciar o escuchar estas importantes categorías. Se hacen sustanciales, porque se refieren a la manera de organizar la comunidad política y a la forma de comprender el poder político (todo un despliegue de vida sistémico). Este trabajo como parte de los avances correspondientes a uno de los objetivos dentro del proyecto de investigación institucional: "La estructura del poder público" (Universidad de San Buenaventura Cali, 2012), pretende relacionar un sentido del poder político alternativo -dentro de un marco teórico- con el ejercicio de gobierno, intentando demostrar, que la manera como sea comprendido ese poder político, juega como un condicionante fundamental de los gobiernos, así como de su relación entre gobernantes y gobernados. Para el desarrollo de este avance, se acude a un análisis metodológico cualitativo, apoyado en la hermenéutica crítica y una suerte de estructuralismo neo-marxista para la comprensión sistémica y categórica del poder político. Esto para establecer, que la metodología del trabajo se basa en la proposición de algunas categorías - dentro de un marco teórico- internalizadas en un contexto propio (el Estado colombiano), que tienen por finalidad, la generación de una propuesta distinta y más próxima a la hora de una praxis de gobierno más justo.

\section{EL PODER POLÍTICO Y EL GOBIERNO}

La política es el más noble ejercicio en el cual deben estar inmersos todos los ciudadanos de una comunidad, de un Estado y del mundo -como pretensión democrática-. El poder político y las formas de gobierno han ocupado desde siglos atrás, diversos análisis y apreciaciones de los más importantes pensadores, así como de ciudadanos desprevenidos y espontáneos. En el caso de un autor como Bobbio, se puede observar, que frente a la variedad de las formas de gobierno son posibles tres posiciones: a) Todas las formas existentes son buenas; b) Todas las formas son malas, y c) Entre las formas de gobierno algunas son buenas y otras son malas. 
En términos generales se puede decir que la primera posición es la de una filosofía relativista e historicista, según la cual cada forma de gobierno es adecuada para la situación histórica concreta que la ha producido (y que no podría producir otra diferente): en la conclusión de Ciencia nueva, Vico habla de "una eterna república natural, en cada una de su especie óptima”. Un ejemplo de la segunda posición la vemos en Platón, según el cual todas las formas de gobierno reales son malas, en cuanto son una degeneración de la única forma óptima que es la ideal. La tercera posición es la más frecuente: habiendo sido teorizada en una obra que ha hecho época en la historia de la filosofía política, en la Política de Aristóteles, podemos llamarla aristotélica (Bobbio, 2010:11). Pero todas estas formas de gobierno sin duda alguna, se encuentran enmarcadas en una equívoca concepción de poder político, una de las más influyentes hasta el día de hoy, es precisamente la de Max Weber bajo su teoría de las estructuras de poder. Dice por ejemplo:

Lo común a todas las formaciones políticas es el empleo de la fuerza; lo que las diferencia es el modo y el grado en que usan o amenazan usar dicha fuerza contra las demás organizaciones políticas. Esas diferencias determinan, a su vez, la conformación y el destino específicos de las comunidades políticas. La "expansividad" no se da en igual medida en toda formación política: algunas se caracterizan por no luchar por la expansión exterior de su poderío o por no mantener un contingente de fuerzas dispuestas a adquirir poderío sobre otros territorios o comunidades, sea mediante la anexión o colonización de los mismos (Weber, 1987: 9).

Esta concepción es una justificación de dominación que ha hecho tradición. Es una exposición propia de la razón instrumentalista que posee la visión moderna europea. La manera no oculta de permitir la colonización y el sometimiento de otras naciones, entendiendo al poder de una manera falaz y reduccionista, como un significativo meramente de fuerza, en últimas, de violencia. Por ello, no es extraño y mucho menos "reprochable" para algunos gobiernos, pensar que una forma de buen gobierno está trazada por el uso legal de la fuerza, la resolución de conflictos a través de las armas y otras herramientas de sometimiento, o la imposición agresiva y expansionista de un Estado sobre otro. Este argumento weberiano de gobierno fundamentado en un poder político dominante, se encuentra aun más respaldado, cuando indica que:

El comportamiento hacia el exterior de las estructuras de poder puede estar motivado por las pretensiones de "prestigio" de sus miembros. Está empíricamente demostrado que las reivindicaciones de prestigio han participado siempre en el origen de las guerras [...] Ese deseo de prestigio, manifestado en la forma de un deseo de poder para la propia formación política, encuentra sus exponentes 
naturales y primarios tanto en los señores feudales como en los oficiales y burócratas modernos. Su propio poder, así como el prestigio sustentado en él, emana del poder de su propia formación política (Weber, 1987: 10).

Este motivo de prestigio, que hoy es el mismo motivo de las multinacionales de la minería y el petróleo -entiéndase feudalismo global y burguesía trasnacionales el motivo economicista de determinación política. Es decir, la razón instrumental economicista preferente sobre la política, la ecología, la comunidad y la vida. No es erróneo el planteamiento de Weber al decir de las guerras y dicho prestigio, pero qué mejor para el mundo actual, entender ese prestigio como algo natural e inevitable, como algo dado para algunos en su formación y negados para otros por la misma razón formativa, donde estratégicamente se cree y se ha hecho creer, que el poder está en cabeza de quienes ostentan el prestigio adquirido por la fortuna de ser formados para gobernar e imponerse sobre una suerte de sujetos llamados a ser para siempre, unos meros "gobernados".

A pesar de la trascendencia del poder político, el mundo moderno y contemporáneo se ha encargado de confundir el poder político con otras manifestaciones, como por ejemplo: la fuerza, la capacidad militar, la riqueza económica, el control, la imposición, entre otras. Por eso es entendible su dinámica de poder respecto a América Latina, puesto que:

Las potencias metropolitanas durante toda la Modernidad, y hasta el presente ante el mundo postcolonial, han ejercido una "doble moral". Hacia adentro (ad intra) han propuesto un "Principio democrático" como participación simétrica de los afectados en la creación de instituciones que organicen la procedimentalidad legítima, pero excluyendo de dicha participación, a los esclavos, a los indios, a los pueblos coloniales durante la época colonialista, y muchos otros. Posteriormente nunca los pueblos postcoloniales pudieron acceder a una soberanía popular real, sino que siguieron ejerciéndose sobre ellos presiones, opresiones o exclusiones políticas, económicas, culturales, religiosas y militares (Dussel, 2007: 286).

Por eso, debemos revisar lo que tenemos como poder político y lo que podríamos proponer como poder político alternativo, de manera que pueda, apropiarse una forma de gobierno distinta, más completa, más democrática, más latinoamericana y más justa, para no tener que quedarnos entre los restos de un gobierno originariamente sinónimo de dominación, donde simplemente se cuestiona ese gobierno desde la óptica de una buena o mala dominación.

El poder político es un referente de análisis teórico-práctico a partir del cual se puede hacer un acercamiento crítico al ejercicio de gobierno -hago énfasis en Colombia-. Para esto, los planteamientos del trabajo tendrán un enfoque desde la Politica de la liberación; toda una obra de filosofía política apropiada para revisar 
los siguientes puntos (contenidos de investigación concreta): en primer lugar, lo politico como falacia reduccionista; en segundo lugar, los niveles y las esferas de lo politico (relación con el gobierno); por último y a manera de conclusión, el poder politico y el buen gobierno (retos de la ciudadanía).

\section{FALACIAS REDUCCIONISTAS DE LO POLÍTICO. HACIA LOS RESTOS DE UN GOBIERNO}

La filosofía política y la ciencia política como es de esperarse, se han dado a la tarea de realizar una descripción del concepto de lo político. De ahí, que se hayan elaborado variadas e importantes descripciones de este concepto por parte de algunos autores, que por lo general consideraron la determinación de lo político a partir de un solo momento, olvidando la complejidad de esto (la articulación con otros momentos necesarios, aunque posiblemente insuficientes) y las consecuencias de elaborar una reductiva concepción (gobiernos reduccionistas). Por ejemplo, en el caso de C. Schmitt (la politica sólo como competencia amigo-enemigo) se cree en una sola determinación de tipo voluntarista y se queda encerrado en un nivel estratégico, cuando reduce lo político a la famosa dialéctica de gobierno y partido político trazada por la relación amigo-enemigo, olvidando que esa amistad y enemistad se construye sobre la base de criterios y principios que los hace distintos y los prepara para la realización de acciones o la instalación de instituciones, donde se verifica la trascendencia de las acciones y la intersubjetividad de la ciudadanía y los gobiernos como elemento de dinamismo político.

Otro ejemplo se puede leer a la luz de la política como supraestructura de lo económico, aquí la preeminencia del economicismo es tal, que la política pasó poco a poco a convertirse en una posibilidad negada y, con ello, la ciudadanía como sujeto real y de poder, de tal manera, que el economicismo ingenuo y metafísico negó la posibilidad de la política -y de un buen gobierno-. La política era una instancia supra-estructural secundaria. "Era necesario usar la política para aumentar las contradicciones del capitalismo, ya que "cuanto más pronto llegara la "etapa" capitalista a su culminación se podría pasar necesariamente al socialismo. El economicista era antipolítico [...] la política se transformó en la administración total de la comunidad social" (Dussel, 2009: 32).

Por eso, en el marco de la Unión Soviética, los partidos políticos desaparecen junto con los diferentes proyectos ideológicos y el único pensamiento político de gobierno legal es el del Comité Central, el cual es meramente burocrático, centralista y poco o nada democrático. Se piensa que la economía es determinista y última instancia de todo el orden vigente, de modo que la política es condicionada y obligada por los axiomas economicistas, olvidando que la política no es ninguna 
supraestructura. Puesto que, "la política se juega en un campo de relativa autonomía, propio, insustituible, sin última instancia. La vida humana es la sola última instancia de todas las instancias o campos" (Dussel, 2009: 33).

La complementariedad entre el campo económico y el campo político es lo que debe darse, donde el campo económico le ofrece al campo político -dentro del cual se encuentran los gobiernos- una esfera material, una instancia de contenido, mientras que el campo político comparte con el económico, su formalidad, brindándole la legitimidad y permitiendo la gobernabilidad de los recursos; es precisamente la mutua determinación que encabeza el gobierno (ciudadanía representativa). La dimensión económica es importante pero no suficiente, como tampoco lo es la dimensión política; la ciudadanía cuenta dentro de sus redes sistemáticas de actuación y funcionalidad, al mercado, pero también, cuenta con un sistema de partidos políticos, un sistema electoral de votación e inclusive con un sistema jurídico de derechos fundamentales en el caso de algunos Estados Constitucionales, donde existen algunos instrumentos mediante los cuales, se hace y se controla un gobierno. Entendiendo, que las instituciones en cuanto tales son mediaciones de factibilidad. Hacen posible (factibles) usar medios apropiados para cumplir los fines asignados -sería ejercicio de la razón instrumental o estratégica, en el sentido de M. Weber o M. Horkheimer.

Pero de manera incondicional, en el campo político, y en todo sistema político, "son necesarias instituciones no sólo materiales (para reproducir y aumentar la vida del ciudadano) o de legitimidad (para operar dentro del consenso mutuamente aceptado), sino igualmente de instrumentos administrativos que permitan cumplir con los fines" (Dussel, 2006: 66). El ciudadano gobernante y el ciudadano gobernado están configurando constantemente un poder, el poder de la ciudadanía, como una ciudadanía crítica consciente de su complejidad, de su coherencia, de su responsabilidad funcional, de su interdependencia material, formal y factible, de su realidad y de los problemas que atentan contra la última instancia, es decir, contra la producción, reproducción y desarrollo de la vida humana en comunidad. Esto se puede significar cuando:

El principio normativo que rige la intervención en las operaciones e instituciones del sistema económico (hoy capitalista) debe ser siempre que la producción, reproducción y aumento de la vida humana es el criterio que evalúa el proceso productivo y sus efectos como totalidad, incluyendo el mercado, los capitales nacionales y trasnacionales, el capital financiero, etcétera (Dussel, 2006: 137).

También se puede mirar otra de las variedades de reduccionismo de lo político, cuando se concibe solo como afirmación o como la absoluta negación de los principios normativos. En estas dos posiciones podrían ubicarse a K.O. Apel, por un 
lado y a R. Rorty, por el otro. El primero porque le da una ineluctable importancia a los principios normativos morales con aplicación en la política, siendo acusado de fundacionalista, en cambio Rorty, niega que pueda haber principios normativos en la política. Otros como N. Bobbio, creen que estos principios consisten en ciertas reglas procedimentales al que la normatividad no le adiciona ninguna importancia cualitativa.

Para una ciudadanía crítica, tanto la una como la otra (falacias reductivistas ubicadas en los extremos) no respaldan la articulación política y vital dentro de un gobierno, debido a que si se cae en un exclusivismo principalístico, se descartan las acciones estratégicas llevadas a cabo por los ciudadanos (representantes y representados), y de poco nos sirve tener principios normativos que no busquen ser operables o factibles de manera efectiva a través de la puesta en marcha de dichas acciones, así como tampoco es entendible, el contar con tales principios cuando no se menciona como una parte trascendental dentro de la política a las instituciones, en las cuales tienen espacio las acciones ciudadanas y por supuesto de gobernabilidad, cuando estas son objeto de transformación de dicha ciudadanía y, cuando no corresponden con la producción, reproducción y desarrollo de la vida humana.

Esto genera gobiernos e instituciones fetichizadas, que desconocen y vulneran el origen del poder político como potencia (la comunidad), presentando un cuadro de corrupción, de autorreferenciación política y gubernamental, pues desconoce la obedencialidad ante la comunidad y el poder ciudadano que las constituyeron con miras a la vida humana como última instancia y como fin. Con Rorty la balanza sería inversa pero su resultado el mismo, desequilibrio de la política y del orden que lo sostiene como vigente, pues sin principios normativos las acciones y las instituciones ciudadanas no tienen criterios de orientación, su fundamentación es muy escasa, la estabilidad puede ser inalcanzable y la gobernabilidad no tiene factores deontológicos de medición efectiva y eficaz.

El gobierno (la ciudadanía representativa y representada) debe tener claridad de actuación, de orientación y del horizonte político vigente, ya sea para retroalimentar la permanencia del orden político o para buscar su transformación integral, atemperándose siempre a la vida humana en comunidad como la instancia determinante en todos los niveles de lo político (Acciones, Instituciones y Principios), observando, "cómo los principios inspiran las acciones e instituciones, sin quitarles lo de contingentemente creativo de las acciones y la permanencia y gobernabilidad que permiten las segundas" (Dussel, 2009: 36-37). Esa claridad de actuación tiene unos:

Elementos constitutivos de la sociedad que se configuran como instituciones al interior de ella y que les compete el desarrollo, la protección y el bienestar de la ciudadanía. Estas instituciones son la familia, la sociedad civil y el Estado, que 
deben tener como fin último propiciar la generación de la convivencia, pero no de cualquier manera, pues se tiene que garantizar las condiciones materiales para que los ciudadanos puedan contar con el desarrollo de sus capacidades para la realización de la vida al interior de un Estado Nacional (Urquijo, 2007: 113).

La necesidad de no caer en concepciones reductivas de lo político se puede evitar, aunque no quiere decir que sea suficiente, con la consideración de los niveles (a: Acción político-estratégica, b: Instituciones políticas, c: Principios políticos).

Así la cuestión sería estudiar la complejidad de lo político (dentro del cual se encuentra el gobierno) y observar cómo la necesidad de los principios normativos puede articularse a la contingente incertidumbre de la acción político-estratégica y a la necesidad de las instituciones (los gobiernos) (y también la necesidad de su transformación en el momento debido), mostrando la estructura compleja y mutua determinación de los tres niveles (Dussel, 2009: 36).

\section{LOS NIVELES DE LO POLÍTICO Y EL GOBIERNO}

\section{Nivel de la acción politico-estratégica}

Mediante este nivel, el ciudadano al igual que un gobernante se hace presente públicamente dentro del campo político, busca actuar, busca comunicarse para ser oído y para ser visto. Se caracteriza dicho nivel por su contingencia e incertidumbre, por lo cual, el asunto es tratar de encontrarle una lógica a la acción que la haga empíricamente eficaz y posible (los principios contribuyen a esto). Lo estratégico se da, porque es una acción ciudadana dirigida a otros ciudadanos que se encuentran en los espacios prácticos institucionales, donde pueden presentarse dos opciones, la resistencia o el apoyo a dicha acción por parte de diferentes ciudadanos dentro de la tensión propia del campo político.

Puede ejemplificarse esto, cuando un sector de la ciudadanía (grupos de diversidad y orientación sexual) se agrupa ante la reivindicación de lo que considera una afectación negativa de sus derechos por parte de alguna institución (por acción o por omisión), teniendo como potenciales respuestas de los otros ciudadanos: la aceptación, la reprobación e inclusive la indiferencia.

\section{Nivel de las instituciones politicas y el gobierno}

La repetición en el tiempo y la sistematización de las acciones (sobre todo de las acertadas para la gran mayoría de ciudadanos) fundamenta la necesidad de las instituciones para depositar esas acciones como experiencias exitosas para la 
sostenibilidad, el desarrollo y las funcionalidades requeridas para la organización del poder ciudadano, de su gobierno y para garantizar la vida humana.

Las instituciones contienen las competencias y los roles que deben encarar los ciudadanos, ya sea en un plano institucional material, formal o de factibilidad, esto para señalar que las instituciones deben tener presente el contenido económico, ecológico y cultural, sin perder de vista la legitimidad de esas acciones y decisiones tomadas en esas subesferas materiales, así como su factibilidad cierta y real. Instituciones y gobiernos, que siempre deberán reconocer al poder ciudadano como el poder político que las instituye y las constituye para el ejercicio delegado y obediencial del poder político, poder que no podrá ni debe ser usurpado, ni corrompido por las instituciones (potestas), mucho menos por gobiernos corruptos. Es un ejercicio delegado que está condicionado por la propia ciudadanía, por otras instituciones, e inclusive por los principios normativos y, en esa medida por la propia producción, reproducción y desarrollo de la vida humana.

"Las instituciones son condiciones condicionadas condicionantes" (Dussel, 2006: 57). Son condiciones y mediaciones necesarias para hacer posible la vida humana (material, formal y de factibilidad), condicionan las acciones de los ciudadanos (representantes - representados) (aclarando la existencia de sus derechos, de sus deberes, de sus obligaciones y de sus funciones), pero son condicionadas por los propios ciudadanos, cuando deciden respaldarlas o transformarlas, condicionadas por los principios cuando evalúan su eficacia, forman sus criterios orientadores y sus parámetros de gestión ciudadana y de gobierno. La vida reconoce mucho más su sacralidad, puesto que:

La vida puede considerarse como un conjunto de "funcionamientos" interrelacionados, consistentes en estados y acciones". Si un ciudadano no goza de ciertos funcionamientos básicos como poder nutrirse, gozar de salud física y mental, poder participar en la vida de la comunidad y proporcionarse un proyecto de felicidad, su vida se vería seriamente afectada porque se vulneraría las posibilidades de producción, reproducción y desarrollo de su calidad de vida (Urquijo, 2007: 111).

\section{Nivel de los principios politicos implícitos y el gobierno}

Los principios políticos con su talante normativo permiten complementar mucho más la complejidad de lo político, pues a la contingencia e incertidumbre de las acciones ciudadanas y a la permanencia, confianza y estabilidad que facilitan la intersubjetividad ciudadana y la competencia de los gobiernos, se suman los principios como cuestión normativa de la cual depende el ejercicio delegado del poder político, para que se reconozca el poder político en sus dos categorías 
fundamentales -a lo neomarxista estructural-: la potencia (poder político original de la comunidad política) y la potestas (ejercicio delegado y obediencial del poder político). Puede decirse, que los principios políticos son, por otra parte, principios intrinsecos y constitutivos de la potentia (el poder de la comunidad) y también de la potestas (del ejercicio delegado del poder), ya que cada determinación del poder es fruto de una obligación política que impera como deber a los actores en sus acciones y en cumplimiento de la función de las instituciones.

Los principios políticos constituyen, fortalecen y regeneran por dentro, obligando a los agentes, a afirmar la voluntad de vida, en el consenso factible de toda la comunidad, en sus acciones en vista de la hegemonía (como poder obediencial) y alentando el cumplimiento de las tareas de cada esfera institucional (material, formal de legitimidad y de factibilidad eficaz) (Dussel, 2006: 71).

Los principios son condiciones y presupuestos dados que permiten: el querer vivir como contenido de la comunidad y la posibilidad de gestar el consenso como unidad de potencia (poder ciudadano).

La ciudadanía crítica debe construir y participar de estas exigencias deónticas, pues el poder político por excelencia -la potencia- es el punto de partida y de llegada de la política y, no se puede llegar a una potestas institucional (gobiernos) sino se tienen unas cartas de navegación integrales, categóricas, expresas y exigibles (principios) tanto para los ciudadanos representantes como para los ciudadanos representados en una democracia.

El político profesional debe ser superado por el político por vocación para que el riesgo de la ciudadanía sea menor respecto a las expectativas de cumplimiento de los principios y al interés de justicia implícito en las acciones de quien interioriza conscientemente esos principios. "No es entonces imposible imaginar que el que elige la profesión de político rápidamente acepte las propuestas de Fausto y "venda su alma al demonio", de la fetichización usando el ejercicio del poder para sus propios fines, personales o de grupo. Así nace la política como "profesión" y los partidos políticos como "maquinarias electorales" que imponen sus candidatos burocratizados en beneficio del propio partido" (Dussel, 2006: 35). No obstante la importancia de los representantes, la ciudadanía no queda agotada aquí, pues no solo se alude a estos agentes, sino a aquellos que como participantes de una democracia, demuestran que una ciudadanía transformada y crítica es un poder ciudadano, que fiscaliza, controla y exige a sus gobiernos, responsabilidades, gobernabilidad, efectividad y desarrollo de la vida humana. 
Los restos del buen gobierno o los retos de una ciudadanía para gobernar en Colombia: Un análisis desde el poder político

\section{EL PODER POLÍTICO Y EL GOBIERNO (RETOS DE LA CIUDADANÍA PARA SUPERAR LOS RESTOS DE UN GOBIERNO). CONCLUSIONES PARA EL DEBATE}

El poder político como categoría relevante para la propuesta de un gobierno distinto, requiere de manera concomitante una ciudadanía crítica y democrática respaldada desde las ideas y los planteamientos propios del marco teórico propuesto, la politica de la liberación. En esta categoría encontramos de manera un tanto general, el despliegue teórico-práctico de lo visto anteriormente (niveles y esferas de la política), una categoría que enmarca el campo por antonomasia del gobierno y la ciudadanía, el campo político. Un campo concreto, donde la propuesta se afinca pero se diferencia de otros modelos de poder político ciudadano implementados dentro de algunos tipos de democracia -aun existiendo diversos tipos de democracia, la democracia es el mejor modelo para la concreción del poder político y los gobiernos-.

Para un modelo liberal, "los rasgos comunes son: a) Su individualismo, ya que afirma la primacía moral del ciudadano frente a la exigencia de la sociedad; b) Su carácter igualitarista, en la medida que todos los ciudadanos con el mismo estatus moral y el alcance de la libertad entendida como ausencia de interferencia; c) Su concepción limitada de los poderes del Estado; y d) La neutralidad del Estado sobre las distintas concepciones de vida buena" (Urquijo, 2011: 23). Para un modelo republicano podemos destacar estos puntos: "a) Énfasis en la virtud cívica que deben practicar los ciudadanos, la cual ayuda a combatir la indiferencia y la apatía por los asuntos públicos; b) Ciudadano es quien pertenece y participa de una comunidad política, por lo cual adquiere unos derechos y deberes; y c) El ciudadano participa en la deliberación y en la elaboración de las decisiones públicas" (Urquijo, 2011: 21).

Un gobierno consciente del poder político como potencia y de su mandato obediencial (poder delegado de la ciudadanía) debe intentar hablar desde un poder político creativo y positivo, retomando la libertad y los derechos que se desprenden de ella, al ciudadano libre pero social, a la concepción funcional, armónica e integral de los poderes estatales, a la participación deliberativa de los actores, al sentido de pertenencia de los ciudadanos a una comunidad política, pero también a la capacidad crítica de entender que un poder político debe ser viviente, material, consciente, legitimamente participativo, radicalmente democrático y simétrico en el alcance de sus consensos, superando así, ese reducto de gobierno tradicionalmente formal, excluyente, dominador, autorreferenciado (aquel que como político profesional, sube a las instituciones y no mira quien le delega su poder, sino que siempre ha considerado que es en sí mismo el poder, porque según el sentido del 
poder enseńado, los ciudadanos se entregan al gobernante y no delegan, es decir, quedan vacíos y sin voluntad, con razón la importancia del sufragio universal -una suerte de acto formal de cesión total-).

Un gobierno retado desde la ciudadanía debe ser contextualizado, real y estratégico como hegemón factible de reivindicaciones para la producción, reproducción y desarrollo de la vida humana en comunidad y, por tales razones, un gobierno democrático y crítico de sus decisiones, que reconozca que no es la fuente ni el destino del poder político, que es un constituido del poder mismo. El poder político real es un sujeto colectivo e histórico para la transformación del orden vigente en la medida que ese horizonte de vigencia actual atente contra la instancia de vida humana, la cual es acción, es institución, es gobierno y es principio tanto en lo material, como lo formal y lo factible.

Por lo cual, en este avance -con las críticas que puedan suscitarse-, no hay lugar al poder político como dominación, el poder no se toma, el gobierno no es el origen ni el fin del poder, el poder político nunca se debe, ni puede entregar, el poder político no es la fuerza, ni tampoco son las órdenes bajo amenazas (incluyendo esas exacerbadas leyes existentes), -sentido fracasado de nuestros gobiernos- se trata de superar la concepción de poder-gobierno moderno como "probabilidad de imponer la propia voluntad dentro de una relación social, y la de dominación como probabilidad de encontrar obediencia a un mandato de determinado contenido entre personas" (Weber, 1944: 43). De ahí resulta "la no infrecuente combinación política de fuerza y carencia de poder, impotente despliegue de fuerzas que se consumen a sí mismas, a menudo de manera espectacular y vehemente pero en completa futilidad (Arendt, 2005: 228).

El poder político para una forma de gobierno distinta (un reto de la ciudadanía) conforme a Dussel, E., distingue entre dos categorías: "la "potencia [...] el poder de la comunidad política misma) y la potestas (el poder delegado por representación, ejercido por acciones políticas a través de instituciones)" (2009: 59). El poder lo tiene siempre y solamente la comunidad política (la ciudadanía) aunque en ocasiones vulnerado y violentado de tal forma que es silenciado o instrumentalizado -objetivo de buena parte de los medios de comunicación nacionales-. Se denomina "potencia al poder que tiene la comunidad como una facultad o capacidad que le es inherente a un pueblo en tanto última instancia de la soberanía, de la autoridad, de la gobernabilidad, de lo político" (Dussel, 2006: 27). Es ese poder originario e indeterminado aún (potencia), el que requiere una existencia real, empírica y diferenciada a través de lo que se denomina la potestas, que es, "el ejercicio delegado del poder político -donde se debe ubicar realmente el gobierno-, es la necesaria institucionalización del poder de la comunidad, del pueblo" (Dussel, 2006:30). Esta potestas, este gobierno que es funcional a la ciudadanía, debe reconocer siempre su origen y respetar al sujeto colectivo y fundante, que le delega el ejercicio del poder: la ciudadanía. 
El poder político mientras siga siendo pensado y apreciado como esa fuerza dominante y de imposición ya sea por recursos, por imposición o por armas, tendremos restos de un gobierno, porque puede que cuente con la legalidad de una votación o con las funciones y competencias constitucionalmente otorgadas, pero seguirá siendo presa de su ego, pensándose como el origen, el fin y la razón de ser de los Estados - característica evidente en democracias como la colombiana, donde por ejemplo, se mencionan los mecanismos de participación ciudadana, pero su reglamentación legal (Ley 134 de 1994) y de factibilidad es un factor fallido y fracasado, donde las políticas públicas de atención al desplazamiento forzado interno, han sido paquidérmicas y rogadas mediante diversas acciones, que incluyen la protesta y la acción judicial de tutela (T-025 de 2004)-.

El reto de un gobierno más democrático, guarda una estrecha relación con el desarrollo de un poder político positivo (creativo, organizado) en todos sus momentos (niveles y esferas), debiendo reconocer y garantizar, que la ciudadanía se erija como una importante clave para la integración, la movilidad y el aterrizaje real de esos momentos.

Recuérdese a Arendt, cuando dice, que "el único factor material indispensable para la generación de poder es el vivir unido del pueblo. Y quienquiera que, por las razones que sean, se aísla y no participa en ese estar unidos, sufre la pérdida de poder y queda impotente, por muy grande que sea su fuerza y muy válidas sus razones" (2005:227). Entonces, el poder político como dominación no tiene cabida en un gobierno democrático - podría discutirse si en realidad puede darse un gobierno democrático cuando su sentido del poder es negativo y dominante- y para ello, tenemos el reto de construir una ciudadanía consciente de ser el máximo gobierno, configurada desde una concepción positiva, creativa, más justa y transformadora del poder político, que no es más que la propia comunidad, la inherente ciudadanía inmersa y dinamizadora de las acciones, las instituciones y los principios, esa ciudadanía -al menos para Colombia-que debe saberse como gobierno (fiscalizadora, mandante, vinculante, activa y participativa) y que puede formar y transformar a los ciudadanos con vocación política, para ser los verdaderos delegatarios (gobierno) al servicio de un único poder político, la ciudadanía. 


\section{REFERENCIAS}

Arendt, Hannah. La condición humana. Barcelona: Paidós Surcos, 2005.

Bobbio, Norberto. La teoría de las formas de gobierno en la historia del pensamiento politico. México: Fondo de Cultura Económica, 2010.

Dussel, Enrique. Hacia una filosofía politica critica. Bilbao: Descleé de Brouwer, 2001.

Dussel, Enrique. Veinte tesis de politica. México: Siglo XXI Editores, 2006.

Dussel, Enrique. Materiales para una politica de la liberación. México: Plaza y Valdés Editores, 2007.

Dussel, Enrique. Política de la liberación. Arquitectónica. Vol II. España: Trotta, 2009.

Universidad de San Buenaventura Cali. La estructura del poder público, 2012.

Urquijo, Martín. La ciudadanía reexaminada. Cali: Facultad de Humanidades, Universidad del Valle, 2007.

Urquijo, Martín. Ética, ciudadanía y democracia. Elementos para una ética ciudadana. Cali: Universidad del Valle, 2011.

Weber, Max. Economia y sociedad. Esbozo de sociología comprensiva. México: Fondo de Cultura Económica, 1944.

Weber, Max. Estructuras de poder. Buenos Aires: Editorial Leviatán, 1987. 